\section{Chronic paroxysmal hemicrania: first reported British case}

We report the first British case of chronic paroxysmal hemicrania, a rare but debilitating form of headache in which treatment with indomethacin immediately abolishes the attacks.

\section{Case report}

A 22 year old woman was referred with an 11-year history of headaches. These had occurred every day apart from during two periods, one when she was 13 and one when she was 16, when she had been free of headaches for three and six months respectively. During the first five years the headaches had lasted for only 15 minutes and had rarely occurred more than once a day, but they had progressively become longer and more frequent. A presentation they were lasting one to two hours each day, during which time she had several attacks of excruciating pain that lasted for five to 10 minutes, with a duller pain between each exacerbation. She therefore had 15-20 attacks each day, a large proportion of which occurred at night.

The pattern of the headache was constant. It began as a severe sharp stabbing pain above the left ear and in a few seconds spread to the whole of the left side of the face, left anterior scalp, and occasionally around the left common carotid artery. It occurred at any time and woke her from sleep three or four times each week. It was associated with lacrimation of the left eye, blockage of the left nostril, and left ptosis. It could be precipitated by movements of the neck.

There were no abnormal signs on examination apart from bruising of both upper arms where she gripped herself during attacks. When observed during an attack, precipitated by neck flexion, she developed appreciable bradycardia ( 40 beats/minute, regular) despite being in severe pain. Left ptosis and oedema of the upper eyelid and ipsilateral pupillary constriction developed within two minutes of the start of this pain.

She was fully investigated on several occasions. A computed tomogram, skull and sinus $x$-ray films, and an electroencephalogram were all normal No dental abnormality had been found, although impacted wisdom teeth had been extracted in 1978 with no change in the frequency or severity of the headaches, which did not respond to any analgesics. She had been treated with many drugs without success.

Chronic paroxysmal hemicrania was diagnosed and indomethacin $25 \mathrm{mg}$ thrice daily prescribed. The headaches immediately became much milder and stopped totally after five days. They returned briefly three months later during an episode of severe gastroenteritis,'when presumably the indomethacin was not being absorbed, but were relieved as soon as she recovered. She remained symptom free at follow-up after nine months.

\section{Comment}

Chronic paroxysmal hemicrania was first described in a preliminary report in $1974,{ }^{1}$ with a full report in $1976 .{ }^{2}$ A review of the condition in $1980^{3}$ included eight well-documented cases and 10 possible cases There are thought to have been about 40 cases world wide ( $O$ Sjaastad, personal communication).

Chronic paroxysmal hemicrania may be differentiated from ordinary cluster headache by three features. It occurs predominantly in female patients; many attacks occur each day (15 or more in 24 hours) which are of shorter duration than cluster attacks; and there is a prompt and complete response to indomethacin.

As in our patient there is often a phase during which the pattern of attacks is atypical. Indomethacin is the only non-steroidal antiinflammatory drug that has been shown to be effective in this condition it is not effective in ordinary cluster headache though is useful in other forms of headache-for example, cluster headache variant, ${ }^{4}$ in which numerous brief, knifelike pains occur in several parts of the head and there is prolonged benign exertional headache. 5 The required dosage of indomethacin varies considerably, most patients responding to $75 \mathrm{mg}$ a day, although occasionally $250 \mathrm{mg}$ a day or as little as $12.5 \mathrm{mg}$ a day are necessary; thus it is important to titrate the patient's response against the dosage.

We thank Dr O Sjaastad, University of Trondheim, for helpful comments

1 Sjaastad O, Dale I. Evidence for a new (?) treatable headache entity. Headache 1974;14:105.

- Sjaastad O, Dale I. A new ( ?) clinical headache entity "chronic paroxysmal hemicrania". Acta Neurol Scand 1976;54:140.
"Sjaastad O, Apfelbaum R, Caskey W, et al. Chronic paroxysmal hemicrania (CPH). The clinical manifestations. A review. Ups f Med Sci 1980;3 suppl:27-33.

4 Medina JL, Diamond S. Cluster headache variant. Spectrum of a new headache syndrome. Arch Neurol 1981 ;38:705-9.

5 Diamond S, Medina JL. Prolonged benign exertional headache: clinical characteristics and response to indomethacin. Adv Neurol 1982;33:145-9.

(Accepted 26 October 1982)

Princess Margaret Migraine Clinic, Department of Neurology, Charing Cross Hospital, London W6 8RF

R G PETTY, BSC, MRCP, research registrar (present appointment: medical registrar, National Heart Hospital, London W1)

CLIFFORD ROSE, FRCP, physician in charge

\section{Dihydrocodeine narcosis in renal failure}

Dihydrocodeine tartrate is commonly used to relieve mild to moderate pain. We report a case of severe narcosis caused by the drug in an anuric patient receiving maintenance haemodialysis.

\section{Case report}

A 41 year old woman was admitted for ligation of unsightly veins around her Cimino fistula after six years' maintenance haemodialysis. Preoperatively she received pethidine $50 \mathrm{mg}$ and promethazine $25 \mathrm{mg}$, and postoperatively two doses of papaveretum $(15 \mathrm{mg}$ and $10 \mathrm{mg}$ ). The anaesthetic was halothane and nitrous oxide. She made a good recovery and over the next four days received dihydrocodeine $60 \mathrm{mg}$ by mouth three times daily (total $600 \mathrm{mg}$ ) to relieve pain.

Her Cimino fistula became unusable, and on the fourth postoperative day peritoneal dialysis was begun via a catheter inserted under local anaesthesia. No premedication was given. During the following 24 hours her condition deteriorated. She developed myoclonic twitching and became unrousable and hypotensive. Her pupils were constricted, suggesting opiate toxicity. Intravenous naloxone $0.4 \mathrm{mg}$ produced a dramatic improvement her pupils dilated, she woke and hyperventilated, and her blood pressure rose. The improvement was not maintained, and she required multiple injections of naloxone and eventually a continuous infusion of $0.4 \mathrm{mg} / \mathrm{hour}$, which maintained respiratory and circulatory function (total $8.0 \mathrm{mg}$ in 48 hours)

The following day she became acutely hypertensive (blood pressure $200 / 140 \mathrm{~mm} \mathrm{Hg}$ ) and developed grand mal convulsions. A computed tomogram was normal, as was her cerebrospinal fluid. Naloxone was stopped and her blood pressure returned to normal, but she required ventilation.

Three days after the last dose of dihydrocodeine she was still suffering from narcosis; her plasma dihydrocodeine concentration was $0.7 \mathrm{mg} / 1$. Extubation became possible on the eighth day, when her plasma dihydrocodeine concentration was $0.04 \mathrm{mg} / \mathrm{l}$. Her liver biochemistry remained norma throughout.

\section{Comment}

Dihydrocodeine was first prepared in 1911, yet little is known about its pharmacokinetics and pharmacodynamics. ${ }^{1}$ Its unwanted effectsnamely, respiratory and circulatory depression, nausea, vomiting, and constipation-are similar to those of morphine but less pronounced." Although our patient had received other centrally acting depressant drugs four days earlier, the temporal relation of events suggested that her clinical state was due to dihydrocodeine toxicity. The drug concentration was measured by gas chromatography, which dis criminates between dihydrocodeine, naloxone, and dihydrocodeine metabolites.

A dihydrocodeine concentration of $1 \mathrm{mg} / 1$ has been associated with narcosis, and the concentration of $0.7 \mathrm{mg} / 1$ at 72 hours suggests that at the onset of narcosis accumulation of the drug had led to toxic concentrations. Other mechanisms may, however, be postulated, as signs of narcosis persisted and she remained responsive to naloxone despite lower drug concentrations. Such mechanisms include displacement of protein-bound drug in uraemia, resulting in higher free concentrations 